\title{
Strategi Pemasaran Semen Beku Sapi Potong di BIB Lembang
}

\author{
Marketing Strategy of Beef Cattle Frozen Semen in AIA Lembang \\ Eliza Diany ${ }^{1 *}$, Suryahadi ${ }^{2}$, dan Tjahja Muhandri ${ }^{3}$ \\ ${ }^{1}$ Kementerian Pertanian \\ Komplek Cinere Estate, Jl. Terong No. 152 Cinere Depok \\ ${ }^{2}$ Departemen Ilmu Nutrisi dan Teknologi Pakan, Fakultas Peternakan Institut Pertanian Bogor \\ Jl. Ganimedia Blok R4 KPP IPB Dramaga Bogor \\ ${ }^{3}$ Departemen Ilmu dan Teknologi Pangan, Fakultas Teknologi Pertanian Institut Pertanian Bogor \\ Jl. Kamper Kampus IPB Darmaga, Bogor 16680
}

\begin{abstract}
ABSTRAK
Balai Inseminasi Buatan (BIB) Lembang adalah salah satu produsen penghasil semen beku ternak di Indonesia. BIB Lembang sebagai BIB pertama di Indonesia, diberi mandat oleh Pemerintah untuk memproduksi semen beku sapi potong dan sapi perah dalam rangka memenuhi kebutuhan pelaksanaan inseminasi buatan (IB) di Indonesia agar tidak selalu tergantung pada semen beku impor. Tujuan penelitian ini untuk (1) mengidentifikasi dan menganalisis faktor-faktor eksternal dan internal yang memengaruhi pemasaran semen beku sapi potong BIB Lembang, (2) menyusun dan merumuskan dengan tepat strategi pemasaran semen beku sapi potong menyangkut produk, harga, promosi dan distribusi. Dalam penelitian ini dilakukan identifikasi faktor-faktor internal dan eksternal yang memengaruhi pemasaran semen beku sapi potong di BIB Lembang. Berdasarkan faktor internal (kekuatan dan kelemahan) yang dimiliki BIB Lembang dan faktor eksternal (peluang dan ancaman) yang dihadapi BIB Lembang dirumuskan strategi pemasaran semen beku sapi potong dengan matriks Internal Factor Evaluation (IFE) dan External Factor Evaluation (EFE). Skor IFE yang diperoleh oleh BIB Lembang 2,944 dan skor EFE 2,316. Skor total yang terdapat pada matriks EFE menggambarkan dan mengindikasikan posisi perusahaan stabil dalam merespons situasi eksternal. Total skor matriks IFE 2,944, menunjukkan bahwa kekuatan yang dimiliki BIB Lembang dapat mengatasi kelemahan dengan cukup baik. Total skor matriks EFE 2,316, menunjukkan bahwa BIB Lembang cukup baik dalam merespon peluang dan meminimalisasi ancaman. Perpaduan skor IFE dan EFE dalam matriks IE menunjukkan posisi BIB Lembang terletak pada kuadran V, yaitu sel stabilitas dan pertumbuhan. Hal ini berarti BIB Lembang memiliki peluang dipertahankan dan terus dipelihara. Strategi yang cocok untuk daerah ini adalah penetrasi pasar dan pengembangan produk. Hasil analisis SWOT (Strengths, Weakness, Opportunities dan Threats) diperoleh tujuh rumusan alternatif strategi. Selanjutnya dari perhitungan matriks QSP, diperoleh strategi yang paling menarik untuk diterapkan, yaitu meningkatkan sosialisasi dan pembinaan kepada peternak pada aspek manajemen pemeliharaan ternak, pakan, reproduksi dan manajemen kesehatan hewan.
\end{abstract}

Kata kunci: pemasaran, sapi potong, semen beku, strategi

\begin{abstract}
Artificial Insemination Agency (AIA) Lembang is one of frozen semen producer in Indonesia. AIA Lembang as the first received mandate from Government of Indonesia to produce frozen semen of beef cattle and dairy cattle in order to fulfill the of Artificial Insemination (AI) in Indonesia hopefully that Indonesia doesn't always depend on imported frozen semen. The purposes of these research are (1) to identify and analysis external and internal factors that influence marketing of frozen semen of beef cattle from AIA Lembang, (2) to compile and formulate marketing strategy of frozen semen of beef cattle regarding product, price, promotion and distribution. In this research, identifying internal and external
\end{abstract}

\footnotetext{
*) Korespondensi:

Kanpus Kementerian Pertanian Gedung C Lantai 6 - 9, Jl. Harsono RM No. 3 Ragunan, Pasar Minggu, Jakarta Selatan; email: eliza_yunis@yahoo.com
} 
factors that influence marketing of frozen semen of beef cattle were done at AIA Lembang. Based on internal factors (strengths and weakness) and owned by AIA Lembang and external factors (opportunities and threats) facing by AIA Lembang, marketing strategy of frozen semen of beef cattle were formulated by using IFE and EFE matrixs. IFE score for AIA Lembang is 2,944 and EFE score is 2,316. Total score in EFE matrix is describing and identifying that company is in stable position in responding to external situation. Total score for IFE matrix is 2,944, shows that the strength owned by AIA Lembang can over come it weakness fairly enough. Total score EFE matrix is 2,316, shows that AIA Lembang good enough in responding to opportunity and minimize threat. The combination of IFE and EFE scoring in IE matrix shows that AIA Lembang position is in quadrant V namely stability and growth cell. It means that AIA Lembang is stable condition. The good strategies for this region are market penetration and product development. Using SWOT analysis (Strengths, Weakness, Opportunities, and Threats) produce 7 alternative strategy formula. Based on calculation in QSP matrix, the most interesting strategy produced is increase socialization and supervision to farmers on maintainance, feeding and reproduction management as well as animal health management.

Key words: beef cattle, frozen semen, marketing, strategy

\section{PENDAHULUAN}

Sapi potong merupakan salah satu hewan ternak yang potensial dikembangkan untuk memenuhi kebutuhan daging. Berdasarkan hasil PSPK 2011 (BPS, 2011), populasi sapi potong di Indonesia berjumlah 14.824 .373 ekor. Untuk meningkatkan produksi dan populasi sapi potong, dapat dilakukan upaya peningkatan mutu genetik sapi potong. Teknologi yang tepat digunakan dalam upaya peningkatan mutu genetik sapi potong di Indonesia adalah inseminasi buatan.

Kegiatan Inseminasi Buatan (IB) terbukti memiliki keunggulan dibandingkan dengan kawin alam, antara lain penggunaan pejantan unggul, penghematan biaya dan tenaga pemeliharaan pejantan, pencegahan penularan penyakit dan efisiensi reproduksi dapat ditingkatkan (Tolihere, 1981). Berdasarkan hasil penelitian yang dilakukan oleh Shehu et al (2010) dinyatakan bahwa keuntungan penggunaan semen beku pada sapi adalah (1) mengurangi jumlah penggunaan pejantan karena satu ekor pejantan lebih mahal dibanding harga semen beku, (2) mengurangi risiko menyebarnya penyakit, (3) meningkatkan potensi pemilihan genetik yang terbaik, dan (4) meningkatkan keamanan untuk pejantan.

Hall dan Glaze (2013) menyatakan bahwa perkembangan teknologi IB di Amerika berkembang sangat pesat dengan tersedianya semen sexing sapi perah secara komersial selama satu dekade ini, tetapi semen sexing untuk sapi potong baru tersedia lima tahun terakhir. Produsen semen sexing sapi perah telah memiliki katalog 28 jenis pejantan sapi perah sexing. Hasil penelitian ini menunjukkan penggunaan semen sexing betina pada sapi perah, tingkat kebuntingan sapi perah lebih rendah $10-20 \%$ dibandingkan dengan tingkat kebuntingan menggunakan semen biasa. Hasil yang sama juga dilaporkan oleh Cooke et al. (2014) dalam penelitiannya, bahwa penggunaan semen sexing telah berkembang 50 tahun terakhir dan penggunaan semen sexing lebih banyak digunakan pada sapi perah dengan tingkat kebuntingan $70-90 \%$.

Faktor utama yang memengaruhi keberhasilan IB adalah mutu semen beku yang dihasilkan. Mutu semen beku dipengaruhi oleh beberapa faktor, yaitu mutu penjantan yang menghasilkan sperma, cara produksi semen beku sampai saat pelaksanaan IB di lapangan termasuk penanganan terhadap pejantan (BSN, 2008). Menurut Dwiyanto dan Inounu (2009), tingkat keberhasilan IB dipengaruhi oleh (i) mutu semen di tingkat peternak, (ii) kondisi induk (BCS) sapi yang akan di IB, (iii) ketepatan deteksi birahi dan kecepatan melapor kepada petugas, serta (iv) keterampilan inseminator di lapangan, (v) faktor kesehatan hewan dan manajemen pakan untuk mengantisipasi kemungkinan adanya interaksi pengaruh genetik dengan kondisi lingkungan.

Perkembangan teknologi IB diperkenalkan di dunia sejak tahun 1780 oleh peneliti Spallanzani dan melakukan IB pada pada anjing. Tahun 1890, Spallanzani melakukan IB pertama di Prancis pada kuda dan diikuti oleh peneliti dari Rusia, Italia dan Inggris. Selanjutnya tahun 1920 dan 1930 peneliti dari Rusia melakukan IB pertama pada sapi dan diikuti oleh peneliti dari Denmark (Gordon dalam Shehu et al. 2010).

Seiring dengan berkembangnya IB di Indonesia, program perkawinan silang antara sapi lokal (Ongole, Brahman, Madura, Aceh, Pasundan) dengan sapi eksotik (Simental, Limousin) 
juga berkembang pesat. Saat ini sebagian besar peternak rakyat di Pulau Jawa telah melakukan perkawinan melalui IB terutama dengan semen beku sapi eksotik karena (1) berat lahir anaknya lebih tinggi, (2) pertumbuhan yang lebih cepat, (3) adaptasi terhadap pakan dan lingkungan cukup baik, (4) ukuran tubuh dewasa lebih besar, (5) nilai jual lebih tinggi. Pernyataan tersebut sesuai dengan penelitian yang dilakukan oleh Utomo et al. (2013) bahwa berat lahir sapi silangan Simental-PO (peranakan ongole), untuk jantan 35 $\mathrm{kg}$ dan betina $32 \mathrm{~kg}$. Affandhy et al. (2006) melaporkan dalam penelitiannya bahwa bobot lahir sapi silangan Simental-PO dikawinkan dengan pejantan sapi Limousin sebesar $31 \mathrm{~kg}$, sapi silangan Limousin-PO dikawinkan dengan pejantan Simental bobot lahirnya sebesar $29 \mathrm{~kg}$. Tingginya permintaan peternak terhadap semen beku sapi eksotik, mengakibatkan program perkawinan silang antara sapi lokal dengan sapi eksotik berkembang tanpa terkontrol. Dalam jangka panjang dikhawatirkan sapi lokal semakin berkurang bahkan terancam punah.

Semen beku sapi potong yang diproduksi oleh BIB Lembang yang berasal dari pejantan sapi lokal yaitu sapi Madura, sapi Ongole, sapi Brahman, sapi Pasundan, sedangkan yang berasal dari sapi eksotik yaitu sapi Simental, sapi Limousin, Brangus dan Angus. Saat ini jumlah pejantan sapi lokal perbandingannya cukup jauh dibanding sapi eksotik. Jumlah pejantan sapi lokal sampai tahun 2015 terdiri dari sapi Ongole 14 ekor, sapi Brahman 13 ekor, sapi Madura 5 ekor, sapi Aceh 4 ekor dan sapi Pasundan 2 ekor.sedangkan pejantan sapi eksotik terdiri dari sapi simental 55 ekor, sapi limousin 52 ekor dan sapi angus 8 ekor.

Dalam kurun waktu lima tahun terakhir semen beku sapi potong lokal yang diproduksi oleh BIB Lembang mencapai 1.563.679 dosis dan telah disebarkan atau didistribusikan sebanyak 1.315.726 dosis, sehingga masih ada stok sebanyak 280.340 dosis. Secara rinci produksi dan distribusi semen beku sapi potong lokal BIB Lembang seperti pada Gambar 1.

BIB Lembang dari tahun 2011-2015 telah mampu memproduksi semen beku sapi potong lokal sebanyak 1.563.679 dosis. Dalam waktu 5 tahun terakhir telah terdistribusi semen beku sapi potong lokal sebanyak 1.315.126 dosis yang terdiri dari distribusi semen beku hibah 949.063 dosis dan penjualan sebesar 366.063 dosis atau penjualan semen beku sapi lokal hanya mencapai $27,83 \%$ (BIB Lembang, 2015).

Permasalahan yang dihadapi oleh BIB Lembang saat ini adalah semen beku sapi potong lokal yang diproduksi oleh BIB Lembang kurang diminati oleh peternak karena berat lahir anak sapi lokal lebih kecil dibandingkan dengan berat lahir anak sapi eksotik. Permasalahan tersebut sesuai dengan hasil penelitian yang dilakukan oleh Wijono et al. (2006), bahwa bobot lahir sapi PO $22 \mathrm{~kg}$. Hal yang sama dilakukan oleh Subiharta dan Sudrajat (2013), bobot lahir sapi PO bervariasi, sapi betina antara $23-35 \mathrm{~kg}$, sedangkan jantan 24-36 kg. Hasil yang sama juga diperoleh oleh Talib et al. (2003) bahwa berat lahir sapi Bali di beberapa provinsi bervariasi, provinsi Nusa Tenggara Timur (NTT) berat lahirnya $11,9 \mathrm{~kg}$, Bali $16,8 \mathrm{~kg}$, Nusa Tenggara Barat (NTB), 12, $7 \mathrm{~kg}$ dan Sulawesi Selatan 12,3 kg.

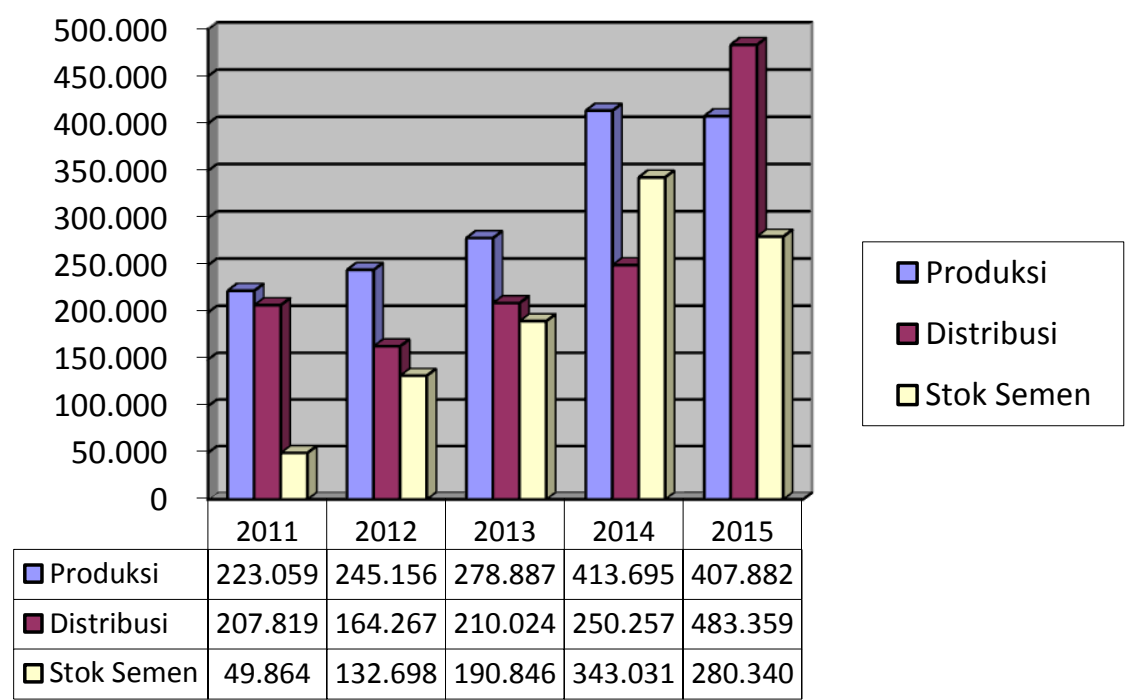

Gambar 1. Produksi dan distribusi semen beku sapi lokal tahun 2011-2015 
Semen beku sapi potong lebih banyak didistribusikan pada peternak secara gratis melalui program kegiatan yang dilakukan oleh Pemerintah melalui Direktorat Jenderal Peternakan dan Kesehatan Hewan. Dengan kondisi tersebut dapat disimpulkan bahwa semen beku sapi potong lokal kurang diminati oleh peternak, kecuali di daerahdaerah tertentu yang masyarakatnya sudah turuntemurun memelihara sapi lokal seperti sapi Madura, Ongole/PO, Brahman, Aceh dan lainlain, telah merasakan keuntungan dari memelihara sapi tersebut. Kenyataan di lapangan, masyarakat kurang tertarik mengembangkan sapi lokal karena harga jual sapi lokal lebih rendah dibandingkan harga jual sapi eksotik pada umur yang sama, sehingga kebutuhan semen beku sapi potong lokal juga tidak sebanyak kebutuhan semen beku sapi eksotik. Hal tersebut memengaruhi penjualan semen beku sapi potong lokal yang diproduksi oleh BIB Lembang.

Di Lokasi-lokasi tertentu seperti lokasi yang berpotensi sebagai wilayah sumber bibit sapi lokal, masyarakat sudah merasakan keuntungan mengembangkan sapi lokal seperti sapi Brahman dan dan sapi Ongole, sehingga mampu meningkatkan pendapatan peternak di lokasi tersebut. Sapi lokal mempunyai keistimewaan yaitu: (1) adaptif, (2) daya reproduksi tinggi, (3) tahan berbagai penyakit/parasit tropis, (4) mutu kulit sangat bagus, serta (5) karkas yang lebih baik (sapi Bali). Dalam kondisi kurang pakan, sapi lokal akan terlihat sangat kurus, tetapi masih mampu untuk berahi, ovulasi, dan bunting (Putro 2009). Sementara itu, hal-hal yang kurang baik pada sapi lokal adalah kurang responsif bila diberi pakan bermutu, Pertambahan Bobot Hidup Harian $(\mathrm{PBHH})$ rendah dan mempunyai bobot potong kecil, serta produksi susu yang rendah. Pada saat musim kering dan kurang pakan, sapi lokal akan melahirkan anak dengan ukuran kecil dan sebagian mati dalam usia dini akibat kekurangan susu.

Penelitian tentang strategi pemasaran pada sapi dilakukan oleh Karupa et al. (2005) untuk mengkaji nilai ekonomi penjualan ternak dari 15 sifat produksi ternak pada sapi Slovakian Pied dengan membandingkan tiga macam strategi pemasaran, yaitu strategi A (ekspor pedet surplus), strategi B (penggemukan pedet surplus) dan strategi $C$ (penggembalaan sapi dara tidak bunting). Hasil penelitian ini menyimpulkan strategi pemasaran A dapat diterapkan pada sifat bobot sapi, strategi B pada sifat bobot setahun dan strategi $C$ pada sifat masa hidup induk. Indriani
(2005) meneliti tentang gambaran pemasaran semen beku sapi potong yang dilakukan oleh BIBD Yogyakarta. Strategi pemasaran meliputi segmentasi pasar, target pasar, penentuan posisi pasar dan bauran pemasaran. Strategi pemasaran yang harus dilakukan oleh BIBD Yogyakarta adalah strategi pertumbuhan agresif, yaitu memanfaatkan atau mempertahankan dengan melakukan kegiatan peningkatan mutu semen beku, penambahan pejantan, mempertahankan SDM professional, peningkatan dukungan dana dari pemerintah, me-ningkatkan pelayanan purna jual semen beku dan mempertahankan harga di bawah standar harga dari pusat.

Penelitian tentang strategi pemasaran semen beku sapi potong belum banyak dilakukan, maka perlu dilakukan penelitian terkait strategi pemasaran semen beku sapi potong terkait produk, harga, distribusi dan promosi di Balai IB Lembang. Tujuan penelitian ini: (1) Mengidentifikasi dan menganalisis faktor-faktor eksternal dan internal yang memengaruhi pemasaran semen beku sapi potong BIB Lembang; (2) Menyusun dan merumuskan strategi pemasaran semen beku sapi potong yang menyangkut produk, harga, distribusi dan promosi.

\section{METODE PENELITIAN}

Penelitian dilaksanakan di Balai IB Lembang, jalan Kiwi Kayu Ambon No. 78 Lembang Bandung. Penelitian ini dilaksanakan bulan Juli sampai Desember 2015. Penentuan responden yang dipilih untuk mengisi kuesioner dilakukan dengan purposive sampling, yaitu responden ditentukan secara sengaja berdasarkan pertimbangan tertentu (Sugiyono, 2012). Responden yang dipilih untuk mengisi kuesioner adalah Kepala BIB Lembang, Kepala Seksi Jasa Produksi, Kepala Seksi Pelayanan Teknis Produksi Semen, Kepala Seksi Pelayanan Teknis Pemeliharaan Ternak. Untuk mengidentifikasi dan mengevaluasi secara lebih mendalam faktor internal (kekuatan dan kelemahan) dan faktor eksternal (peluang dan ancaman) BIB Lembang dalam pemasaran semen beku sapi potong ditentukan tiga orang responden pakar karena dianggap cukup ahli dan menguasai kondisi Balai dan permasalahannya, yaitu: (1) Kepala Seksi Jasa Produksi BIB Lembang, (2) Pakar pendamping BIB Lembang, dan (3) Penanggungjawab kegiatan produksi dan peredaran semen beku di Direktorat Perbibitan dan Produksi Ternak, Ditjen Peternak- 
an dan Kesehatan Hewan. Dalam wawancara tersebut, responden mengidentifikasi dan mengevaluasi, memberikan bobot dan rating terhadap faktor-faktor strategik yang diuraikan dalam kuesioner.

Data penelitian ini meliputi data primer dan sekunder. Data primer diperoleh melalui wawancara mendalam. Data sekunder adalah data penunjang, yang didapatkan dari dokumendokumen yang dimiliki oleh BIB Lembang, Peraturan Menteri Pertanian, jurnal, studi pustaka, dan dokumen lain yang berkaitan dengan penelitian ini.

Pengolahan dan analisis data menggunakan matriks Internal Factor Evaluation (IFE) untuk menganalisis faktor-faktor internal, mengklasifikasikannya menjadi kekuatan dan kelemahan BIB Lembang, kemudian dilakukan pembobotan. Matriks External Factor Evaluation (EFE) digunakan untuk menganalisis faktor-faktor eksternal, mengklasifi-kasikannya menjadi peluang dan ancaman bagi BIB Lembang, kemudian dilakukan pembobotan.

Selanjutnya pengolahan data menggunakan matrik IE yang merupakan alat untuk menentukan posisi suatu perusahaan pada internal dan eksternal perusahaan. Tujuan penggunaan matriks ini untuk memperoleh strategi bisnis yang lebih detail.

Analisis Strengths, Weaknesses, Opportunities and Threats (SWOT) adalah identifikasi berbagai faktor secara sistematis untuk merumuskan strategi perusahaan. Analisis ini didasarkan pada logika yang dapat memaksimalkan kekuatan (Strenghts) dan peluang (Opportunities), namun secara bersamaan dapat meminimalkan kelemahan (Weekness) dan ancaman (Threats). Proses pengambilan keputusan strategik selalu berkaitan dengan pengembangan misi, tujuan, strategi dan kebijakan perusahaan. Matriks ini menghasilkan empat set alternatif strategik, yaitu strategi SO, strategi ST, strategi WO dan strategi WT (Rangkuti, 2005).

Matriks perencanaan strategis kuantitatif atau Quantitative Strategic Planning Matrix (QSPM) merupakan tahap akhir dari perumusan strategik obyektif yang mengindikasikan alternatif strategi terbaik. QSPM terdiri atas empat komponen, antara lain (1) bobot yang diberikan sama dengan yang ada pada matriks EFE dan IFE, (2) nilai daya tarik, (3) total nilai daya tarik, dan (4) jumlah total nilai daya tarik (David, 2006).

\section{HASIL DAN PEMBAHASAN}

BIB Lembang terletak di jalan Kiwi Kayu Ambon No. 78 Lembang Bandung, berjarak sekitar $17 \mathrm{Km}$ dari Kota Bandung. Letaknya sangat strategis untuk pemeliharaan ternak, yakni berada di wilayah Indonesia Barat yang sangat dekat dengan Jakarta sebagai Ibukota Negara.

Lokasi BIB Lembang memiliki ketinggian $1.100 \mathrm{~m} \mathrm{dpl}$, dengan suhu $15-25{ }^{\circ} \mathrm{C}$, curah hujan $2.500 \mathrm{~mm} / \mathrm{tahun}$ dan kelembaban $80-94 \%$. Keadaan alam yang sejuk ini sangat cocok untuk pengembangan sapi. Sebagai BIB pertama di Indonesia, diberi mandat oleh Pemerintah untuk memproduksi semen beku sapi potong dan sapi perah untuk memenuhi kebutuhan pelaksanaan IB di Indonesia agar tidak selalu tergantung pada semen beku impor.

Visi BIB Lembang adalah menjadi produsen semen beku terdepan yang bersih, efisien, dan berprestasi melalui teknologi IB untuk kesejahteraan masyarakat peternakan. Motto BIB Lembang: "Dengan Mani, Membangun Negeri". Misi BIB Lembang adalah: (1) Melaksanakan produksi, penyimpanan dan distribusi serta pemasaran semen beku dalam rangka pelayanan prima kepada masyarakat, (2) Menggali potensi penerimaan negara bukan pajak (PNBP) melalui optimalisasi pemanfaatan aset dalam menunjang tugas pokok dan fungsi balai, (3) Menyelenggarakan dan menggerakkan penyempurnaan teknik dan metode pengembangan inseminasi buatan, (4) Meningkatkan kemampuan sumber daya manusia (SDM) peternakan melalui pelatihan/magang/ bimbingan teknis, (5) Mendorong terciptanya peluang dan kesempatan kerja mandiri untuk peningkatan kesejahteraan masyarakat peternak.

Jumlah karyawan BIB Lembang 90 orang, yang terdiri dari 88 PNS, 2 orang CPNS dan 14 orang karyawan kontrak. BIB Lembang dipimpin oleh seorang Kepala Balai dan dibantu oleh tiga orang Kepala Seksi dan satu orang Kepala Sub Bagian Tata Usaha. Kepala Balai, Kepala Seksi dan Kepala Sub Bagian Tata Usaha merupakan jabatan struktural. Dalam melaksanakan tugas Balai, kepala Balai juga dibantu oleh kelompok jabatan fungsional seperti Pengawas Bibit Ternak, Pengawas Mutu Pakan, Medik Veteriner, Paramedik Veteriner dan sejumlah jabatan fungsional lainnya berdasarkan bidang masing-masing.

Dalam menjalankan proses produksi semen beku ternak unggul, BIB Lembang memiliki sarana dan prasarana cukup modern, terutama mesin dan peralatan produksi semen beku. Saat 
ini luas keseluruhan lahan BIB Lembang $\pm 22,55$ ha dengan rincian luas bangunan + kandang + jalan \pm 4 ha dan luas kebun rumput 18,55 ha.

BIB Lembang mengadopsi teknologi dari Selandia Baru untuk teknik produksi semen beku. Laboratorium BIB Lembang telah terakreditasi oleh Komite Akreditasi Nasional (KAN) dan telah menerapkan sistem manajemen mutu sesuai ISO : 17025 : 2008 dan ISO 9001: 2008. Peralatan yang ada berasal dari Prancis dan Jerman seperti container kapasitas 500-600 liter, dummy cow, mikroskop yang terhubung langsung dengan komputer, mesin printing-sealing-fealing yang ada saat ini sangat mutakhir dan peralatan laboratorium cukup lengkap untuk memproduksi semen beku.

Semen beku yang diproduksi BIB Lembang terdiri dari semen beku sapi potong, sapi perah, kerbau, kambing dan domba. Semen beku yang diproduksi berasal dari pejantan-pejantan yang sudah lolos uji penyakit hewan menular, strategi yang dipersyaratkan Direktorat Kesehatan Hewan Ditjen Peternakan dan Kesehatan Hewan. Jumlah pejantan sapi potong yang ada saat ini sebanyak 36 ekor (bangsa sapi Ongole, sapi Brahman, sapi Madura dan sapi Aceh). Jumlah semen beku sapi potong lokal yang diproduksi IB Lembang selama lima tahun terakhir 1.563.679 dosis.

Pola distribusi semen beku BIB Lembang dengan dua cara, yaitu: (1) Distribusi semen beku sapi potong berdasarkan target yang ditetapkan oleh Direktorat Jenderal Peternakan dan Kesehatan Hewan sesuai permintaan Dinas Peternakan Provinsi/Kabupaten. Semen beku hibah ini terutama untuk program dan kegiatan pembibitan dan pengembangan sapi potong lokal, serta diberikan secara gratis kepada peternak di seluruh Indonesia; (2) Pembelian langsung. Konsumen dapat secara langsung membeli semen beku berdasarkan ketersediaan semen beku yang ada. Pembeli semen beku potong berasal dari asosiasi inseminator, dokter hewan mandiri, Dinas Peternakan Provinsi/Kabupaten, koperasi dan swasta. Dalam waktu lima tahun terakhir telah terdistribusi semen beku sapi potong lokal sebanyak 1.315.126 dengan dosis terdiri dari distribusi semen beku hibah 949.063 dosis dan penjualan sebesar 366.063 dosis atau penjualan semen beku sapi lokal hanya mencapai $27,83 \%$. Semen beku sapi potong lebih banyak didistribusikan pada peternak secara gratis melalui program kegiatan yang dilakukan oleh Pemerintah melalui Direktorat Jenderal Peternakan dan Kesehatan Hewan. Dengan kondisi tingkat penjualan sapi potong lokal 27,83\%, dapat disimpulkan bahwa semen beku sapi potong lokal kurang diminati oleh peternak. Harga semen beku sapi potong yang dijual di dalam negeri cukup terjangkau. Harga semen beku sapi potong sexing harganya Rp7.000 per dosis dan semen beku unsexng Rp36.000 per dosis, tetapi di lapangan peternak tidak berminat untuk membeli semen beku sapi potong lokal.

BIB Lembang dalam mempromosikan keunggulan semen beku sapi potong melalui beberapa cara, yaitu (1) Internet, (2) Mengikuti pameran baik dalam maupun luar negeri (ASEAN), (3) Membagikan leaflet, brosur, poster, katalog kepada inseminator, koperasi, perusahaan, dinas peternakan provinsi, dinas peternakan kabupaten, (4) Mengunjungi langsung konsumen seperti Dinas Peternakan Provinsi dan Kabupaten. Pada saat kunjungan tersebut, tim pemasaran semen beku melakukan presentasi dan memasarkan produk semen beku yang dimiliki BIB Lembang. Sampai saat ini BIB Lembang belum mempromosikan produknya melalui media cetak dan elektronik, karena biaya untuk iklan di media tersebut cukup tinggi. BIB Lembang memberikan pelayanan purna jual kepada konsumen dengan cara melakukan penggantian terhadap produk semen beku yang rusak sebelum digunakan. Selain itu pelayanan purna jual dilakukan dengan memberikan pelayanan pemeriksaan reproduksi sapi peternak yang sudah 2 kali di IB belum bunting.

\section{Perumusan Strategi Pemasaran}

\section{Analisis Matriks IFE}

Berdasarkan analisis matriks IFE diperoleh skor tertinggi faktor kekuatan pada mutu semen beku dan SDM handal dengan skor 0,444. Skor terendah pada faktor kekuatan adalah harga semen beku terjangkau, yaitu 0,167. Pada faktor kelemahan, skor tertinggi adalah jumlah pejantan lokal sedikit dan biaya promosi terbatas, 0,250. Skor terendah adalah promosi masih kurang yaitu 0,111. Total skor matriks IFE 2,944, menunjukkan kekuatan yang dimiliki BIB Lembang dapat mengatasi kelemahan dengan cukup baik. Total skor matriks IFE dapat dilihat pada Tabel 1.

\section{Analisis Matriks EFE}

Hasil analisis matriks EFE dapat diketahui skor tertinggi pada peluang adalah kemajuan teknologi 0,421. Skor terendah pada peluang adalah kapasitas produksi 0,237. Pada ancaman, skor tertinggi 0,211 terdapat pada kondisi 
ekonomi masyarakat. Skor terendah pada kebijakan ekspor semen beku dan pemotongan sapi betina produktif 0,079 . Total skor matriks EFE 2,316, menunjukkan bahwa BIB Lembang cukup baik dalam merespon peluang dan meminimalisasi ancaman.

Tabel 1. Hasil evalusi faktor internal BIB Lembang

\begin{tabular}{|c|c|c|c|}
\hline Faktor Internal & $\begin{array}{l}\text { Bobot } \\
\text { (a) }\end{array}$ & $\begin{array}{l}\text { Rating } \\
\text { (b) }\end{array}$ & $\begin{array}{l}\text { Skor } \\
\text { (axb) }\end{array}$ \\
\hline \multicolumn{4}{|l|}{ A. Kekuatan } \\
\hline 1. Mutu semen beku terjamin & 0.111 & 4 & 0.444 \\
\hline 2. SDM produksi semen & & & \\
\hline beku handal & 0.111 & 4 & 0.444 \\
\hline $\begin{array}{l}\text { 3. Sarana dan prasarana } \\
\text { memadai }\end{array}$ & 0.833 & 3 & 0.250 \\
\hline $\begin{array}{l}\text { 4. Harga semen beku } \\
\text { terjangkau }\end{array}$ & 0.055 & 3 & 0.167 \\
\hline 5. Pelayanan prima & & & \\
\hline \multirow{2}{*}{$\begin{array}{l}\text { 6. Mutu genetik pejantan } \\
\text { bagus dan bebas penyakit } \\
\text { menular }\end{array}$} & 0.111 & 4 & 0.440 \\
\hline & 0.083 & 3 & 0.250 \\
\hline \multicolumn{4}{|l|}{ B. Kelemahan } \\
\hline $\begin{array}{l}\text { 7. Jumlah pejantan lokal } \\
\text { sedikit }\end{array}$ & 0.083 & 2 & 0.250 \\
\hline $\begin{array}{l}\text { 8. Sulit mendapatkan } \\
\text { pejantan lokal }\end{array}$ & 0.111 & 1 & 0.167 \\
\hline 9. Promosi masih kurang & 0.083 & 3 & 0.111 \\
\hline 10. Biaya promosi terbatas & 0.083 & 3 & 0.250 \\
\hline 11. Pemasaran belum optimal & 0.083 & 2 & 0.167 \\
\hline TOTAL & 1.000 & & 2.944 \\
\hline
\end{tabular}

Dari analisis yang dilakukan didapatkan, total yang dibobot pada Matriks IFE 2,944, artinya kekuatan yang dimiliki oleh BIB Lembang dapat mengatasi kelemahan dengan cukup baik. Pada Matriks EFE, skor totalnya 2,316, menunjukkan BIB Lembang mempunyai posisi eksternal sedang. Hal ini berarti bahwa BIB Lembang cukup baik dalam merespon peluang dan meminimalisasi ancaman. Total dari Matriks IFE dan Matriks EFE kemudian dipetakan dalam Matriks IE, sehingga diketahui posisi Balai. Total skor matriks EFE dapat dilihat pada Tabel 2.

\section{Analisis Matriks IE}

Nilai skor total kombinasi matriks IFE dan EFE digunakan untuk mengetahui posisi Balai. Berdasarkan kombinasi skor IFE dan EFE didapatkan matriks IE. Skor matriks IE menunjukkan Balai pada posisi pertumbuhan/stabil. Dari Gambar 2 dapat diketahui bahwa BIB Lembang berada pada kuadran V. Strategi yang cocok untuk kuadran ini adalah penetrasi pasar dan pengembangan produk. Posisi BIB Lembang berdasarkan skor IFE dan EFE dapat dilihat pada Gambar 2.

Tabel 2. Hasil evaluasi faktor eksternal BIB Lembang

\begin{tabular}{|c|c|c|c|c|}
\hline & Faktor Eksternal & $\begin{array}{l}\text { Bobot } \\
\text { (a) }\end{array}$ & $\begin{array}{l}\text { Rating } \\
\text { (b) }\end{array}$ & $\begin{array}{l}\text { Skor } \\
\text { (axb) }\end{array}$ \\
\hline \multicolumn{5}{|c|}{ A. Peluang } \\
\hline 1. & Kemajuan teknologi IB & 0.105 & 4 & 0.421 \\
\hline 2. & $\begin{array}{l}\text { Permintaan semen beku } \\
\text { dari luar negeri }\end{array}$ & 0.105 & 3 & 0.316 \\
\hline 3. & $\begin{array}{l}\text { Pangsa pasarsemen beku } \\
\text { sapi potong masih } \\
\text { terbuka luas }\end{array}$ & 0.105 & 3 & 0.316 \\
\hline 4. & $\begin{array}{l}\text { Program pembibitan sapi } \\
\text { potong }\end{array}$ & 0.078 & 4 & 0.316 \\
\hline \multirow[t]{2}{*}{5.} & $\begin{array}{l}\text { Kapasitas produksi } \\
\text { semen beku sapi potong } \\
\text { lokal }\end{array}$ & 0.078 & 3 & 0.237 \\
\hline & B. Ancaman & & & \\
\hline 6. & $\begin{array}{l}\text { Kebijakan pelarangan } \\
\text { ekspor semen beku sapi } \\
\text { potong }\end{array}$ & 0.078 & 1 & 0.079 \\
\hline 7. & Penyakit hewan menular & 0.105 & 1 & 0.105 \\
\hline 8. & Pasar bebas ASEAN & 0.078 & 2 & 0.158 \\
\hline & $\begin{array}{l}\text { Keberadaan BBIB Singo- } \\
\text { sari dan BIB Ungaran }\end{array}$ & 0.105 & 1 & 0.079 \\
\hline 10. & $\begin{array}{l}\text { Pendapatan peternak } \\
\text { masih rendah }\end{array}$ & 0.105 & 2 & 0.211 \\
\hline 11. & $\begin{array}{l}\text { Pemotongan sapi betina } \\
\text { produktif di masyarakat }\end{array}$ & 0.078 & 1 & 0.079 \\
\hline & TOTAL & 1.000 & & 2.316 \\
\hline
\end{tabular}

\section{Analisis Matriks SWOT}

Matriks SWOT dapat menggambarkan bagaimana peluang dan ancaman eksternal yang dihadapi BIB Lembang pada usaha pemasaran semen beku sapi potong dapat disesuaikan dengan kekuatan dan kelemahan internal. Matriks ini menghasilkan empat sel kemungkinan alternatif strategi, yaitu strategi S-O, strategi $\mathrm{W}-\mathrm{O}$, strategi $\mathrm{W}-\mathrm{T}$, dan strategi $\mathrm{S}-\mathrm{T}$ seperti disajikan pada Gambar 3.

\section{Analisis Matriks QSPM}

Dari hasil analisis Matriks IE dan Matriks SWOT, diperoleh alternatif strategi yang akan diterapkan oleh BIB Lembang. Untuk menentukan prioritas strategi yang paling utama bagi BIB Lembang, dilakukan analisis Matriks QSP. Alternatif-alternatif strategi dimaksud adalah:

1. Memperluas dan mempertahankan jaringan pemasaran yang sudah ada.

2. Memanfaatkan teknologi untuk meningkatkan mutu semen beku sapi potong lokal.

3. Meningkatkan kegiatan promosi semen beku sapi potong lokal. 


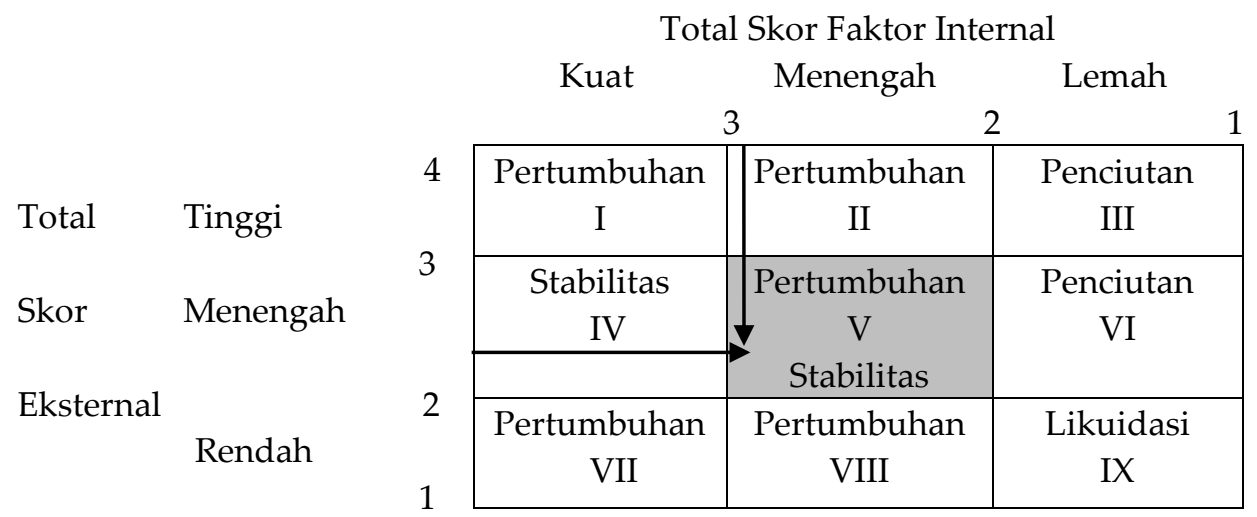

Gambar 2. Hasil analisis Matriks IE

\begin{tabular}{|c|c|c|}
\hline EFE & $\begin{array}{l}\quad \text { KEKUATAN (S) } \\
\text { 1. Mutu semen beku terjamin } \\
\text { 2. SDM produksi handal } \\
\text { 3. Sarana dan prasarana memadai } \\
\text { 4. Harga semen beku terjangkau } \\
\text { 5. Pelayanan prima } \\
\text { 6. Mutu genetik pejantan bagus } \\
\text { dan bebas penyakit menular }\end{array}$ & $\begin{array}{l}\text { KELEMAHAN (W) } \\
\text { 1. Jumlah pejantan lokal sedikit } \\
\text { 2. Sulit mendapatkan pejantan lokal } \\
\text { 3. Promosi masih kurang } \\
\text { 4. Biaya promosi terbatas } \\
\text { 5. Pemasaran belum optimal }\end{array}$ \\
\hline $\begin{array}{l}\text { PELUANG }(\mathrm{O}) \\
\text { 1. Kemajuan teknologi IB } \\
\text { 2. Permintaan semen beku dari luar } \\
\text { negeri } \\
\text { 3. Pangsa pasar semen beku sapi } \\
\text { potong masih terbuka luas } \\
\text { 4. Program pembibitan sapi potong } \\
\text { 5. Kapasitas produksi semen beku } \\
\text { sapi potong }\end{array}$ & $\begin{array}{l}\text { STRATEGI SO } \\
\text { 1. Memperluas dan memper- } \\
\text { tahankan jaringan pemasaran } \\
\text { yang sudah ada (O2, O3, O5, S1, } \\
\text { S2, S4, S5, S6) } \\
\text { 2. Memanfaatkan teknologi untuk } \\
\text { melakukan inovasi semen } \\
\text { beku sapi potong (O1, O3, O5, } \\
\text { S1, S3,S6) }\end{array}$ & $\begin{array}{l}\text { STRATEGI WO } \\
\text { 1. Meningkatkan kegiatan promosi } \\
\text { semen beku sapi potong lokal } \\
(\mathrm{O} 2, \mathrm{O} 3, \mathrm{~S} 3, \mathrm{~S} 4, \mathrm{~S} 5) \\
\text { 2. Meningkatkan kerjasama dengan } \\
\text { Balai Veteriner dan Dinas Peter- } \\
\text { nakan untuk mendapatkan pejan- } \\
\text { tan yang sehat (O2, O3, O5, S2, } \\
\text { S3) }\end{array}$ \\
\hline $\begin{array}{l}\quad \text { ANCAMAN (T) } \\
\text { 1. Kebijakan pelarangan ekspor } \\
\text { semen beku sapi potong } \\
\text { 2. Penyakit hewan menular } \\
\text { 3. Pasar bebas ASEAN } \\
\text { 4. Keberadaan BIB Singosari dan BIB } \\
\text { Ungaran } \\
\text { 5. Pendapatan peternak masih rendah } \\
\text { 6. Pemotongan sapi betina produktif } \\
\text { di masyarakat }\end{array}$ & \begin{tabular}{l}
\multicolumn{1}{c}{ STRATEGI ST } \\
1. Mempertahankan mutu semen \\
beku dan meningkatkan \\
pelayanan purna jual (T4, T5, \\
S1, S2, S4) \\
2. Memberikan pelayanan teknis \\
kepada peternak (T5, T6, S2, S5)
\end{tabular} & $\begin{array}{l}\quad \text { STRATEGI WT } \\
\text { Meningkatkan sosialisasi dan } \\
\text { pembinaan kepada peternak di } \\
\text { aspek manajemen pemeliharaan } \\
\text { ternak, pakan, reproduksi dan } \\
\text { manajemen kesehatan ternak (T5,T6, } \\
\text { W1, W2) }\end{array}$ \\
\hline
\end{tabular}

\section{Gambar 3. Hasil analisis Matriks SWOT}

4. Meningkatkan kerjasama dengan Balai Veteriner dan Dinas untuk mendapatkan pejantan lokal yang sehat.

5. Mempertahankan mutu semen beku dan meningkatkan pelayanan purna jual.

6. Memberikan pelayanan teknis kepada peternak.

7. Meningkatkan sosialisasi dan pembinaan kepada peternak dalam aspek manajemen pemeliharaan ternak, pakan, reproduksi dan manajemen kesehatan hewan.
Berdasarkan hasil perhitungan dalam matriks QSPM, diperoleh strategi paling tepat adalah meningkatkan sosialisasi dan pembinaan kepada peternak dalam aspek manajemen pemeliharaan ternak, pakan, reproduksi, dan manajemen kesehatan hewan, dengan total nilai daya tarik tertinggi di antara alternatif strategi lainnya 5.4920. Untuk lebih jelas tentang urutan prioritas strategi dari hasil matriks QSPM dapat dilihat pada Tabel 3. 
Tabel 3. Urutan prioritas strategi Matriks QSP

\begin{tabular}{clcc}
\hline No. & \multicolumn{1}{c}{ Alternatif Strategi } & $\begin{array}{c}\text { Total Nilai } \\
\text { Daya Tarik }\end{array}$ & Prioritas \\
\hline 1. & $\begin{array}{l}\text { Meningkatkan sosialisasi dan pembinaan kepada peternak pada aspek } \\
\text { manajemen pemeliharaan ternak, pakan, reproduksi dan manajemen kesehatan } \\
\text { hewan }\end{array}$ & 5.4920 & $\mathrm{I}$ \\
2. & Memperluas dan mempertahankan jaringan pemasaran yang sudah ada & 5.4130 & $\mathrm{II}$ \\
3. & Meningkatkan kegiatan promosi semen beku sapi potong lokal. & 5.3910 & $\mathrm{III}$ \\
4. & Mempertahankan mutu semen beku dan meningkatkan pelayanan purna jual & 5.3240 & $\mathrm{IV}$ \\
5. & Memberikan pelayanan teknis kepada peternak. & 5.3090 & V \\
6. & Meningkatkan kerjasama dengan Balai Veteriner dan Dinas untuk & 5.2360 & VI \\
& mendapatkan pejantan lokal yang sehat. & 4.9100 & VII \\
7. & Memanfaatkan teknologi untuk meningkatkan mutu semen beku sapi potong & & \\
\end{tabular}

\section{Implikasi Manajerial}

Implikasi manajerial dalam pemasaran semen beku di BIB Lembang dapat dirumuskan dalam beberapa langkah strategi berikut:

\section{Aspek Pembinaan}

Dalam upaya mengembangkan dan meningkatkan populasi sapi lokal perlu sosialisasi dan pembinaan secara terus menerus kepada peternak dengan cara memberikan pemahaman bahwa sapi lokal memiliki keunggulan yang tidak dimiliki oleh sapi eksotik, yaitu (1) Daya tahan terhadap panas tinggi; (2) Pertumbuhan tetap baik, walaupun dengan pakan jelek; (3) persentase karkas tinggi dan mutu daging baik; (4) Reproduksi baik, karena dapat beranak setiap tahun.

Peternak agar diberikan pemahaman tentang dampak perkawinan silang, sapi lokal betina di IB dengan semen beku sapi eksotik akan memberikan dampak negatif pada anaknya, terutama peternak yang tidak mampu menyediakan pakan sesuai kebutuhan ternak, yaitu tingkat kesuburannya akan menurun, daya adaptasi akan berkurang, anak yang dilahirkan tidak jelas bangsanya dan dikhawatirkan dalam jangka panjang sapi lokal semakin berkurang dan bahkan terancam punah. Hal ini berdasarkan penelitian yang dilakukan oleh Putro (2008) bahwa semakin tinggi komposisi darah sapi eksotik (Simental/Limousin) akan menurunkan kinerja reproduksi seperti sapi sulit bunting, jarak kelahiran semakin panjang.

Pakan ternak merupakan faktor yang sangat memengaruhi pertumbuhan ternak. Berdasarkan penelitian yang dilakukan oleh Mastika (2003), sapi Bali yang diberikan pakan ternak bermutu, yaitu rumput gajah $60 \%+40 \%$ konsentrat dihasilkan pertambahan bobot badan 760 gram/ekor/hari. Berkaitan dengan hal ini tersebut perlu dilakukan pembinaan dan pe- nyuluhan kepada peternak pentingnya pemberian pakan bermutu, sehingga bobot sapi lokal akan meningkat dan anak yang lahir akan lebih besar. Sapi yang diberikan pakan cukup akan berpengaruh terhadap alat reproduksi sapi betina. Sapi betina yang kurang pakan, badannya akan menjadi sangat kurus dan biasanya sulit birahi. Sapi yang mampu bunting, tetapi kekurangan pakan kemungkinan besar akan terjadi keguguran. Di samping itu faktor kesehatan juga sangat memengaruhi pertumbuhan ternak. Sapi yang sehat akan tumbuh lebih baik dibandingkan sapi yang sakit. Peternak agar diberikan pembinaan untuk pencegahan dan penanganan ternak, agar terhindar dari penyakit hewan menular.

\section{Aspek pemasaran}

BIB Lembang perlu meningkatkan kegiatan promosi untuk menjangkau pasar yang lebih luas strategi yang dapat dilakukan adalah:

a. Memperluas lokasi penjualan semen beku sapi potong lokal dengan memperhatikan potensi wilayah pengembangan sapi potong lokal yang ditetapkan oleh Dinas Peternakan provinsi di Indonesia.

b. Memperkenalkan semen beku sapi potong lokal di wilayah introduksi IB dan pengembangan IB, sehingga peternak tertarik mengembangkan sapi lokal seperti Kalimantan, Sulawesi, Maluku dan Papua. Lokasi penjualan semen beku sapi lokal yang saat ini sudah baik, maka tetap dipertahankan dan ditingkatkan pelayanannya dengan pelayanan purna jual untuk menjaga kepercayaan masyarakat terhadap semen beku sapi potong lokal.

c. Promosi dapat juga dilakukan dengan cara menawarkan kepada peternak dengan melakukan kunjungan langsung melalui kegiatan sosialisasi dan pembinaan, presentasi langsung kepada peternak untuk mempromosikan 
keunggulan semen beku sapi potong lokal dan memberikan pemahaman tentang keunggulan sapi lokal. Kunjungan langsung kepada peternak dilakukan secara berkala dengan bantuan asosiasi inseminator, petugas dinas kabupaten dan karyawan BIB Lembang.

d. Promosi dilakukan dengan melibatkan peternak yang telah berhasil mengembangkan sapi potong lokal menjadi pembicara utama pada acara pembinaan atau penyuluhan di kelompok peternak. Hal ini dilakukan untuk lebih meyakinkan peternak yang belum menggunakan semen beku sapi potong lokal.

e. Promosi semen beku sapi potong lokal dengan cara menggunakan media seperti majalah BIB Lembang, koran Sinar Tani, majalah Trobos, penyebaran poster, leaflet, pamflet dan katalog pejantan sapi potong lokal.

f. Adanya keterbatasan anggaran promosi semen beku membuat BIB Lembang mengalami kesulitan untuk mempromosikan semen beku sapi potong lokal dengan media cetak dan elektronik. Biaya untuk promosi tersebut sangat mahal. Untuk mengatasi masalah tersebut BIB Lembang perlu mengalokasikan anggaran di tahun depan atau merevisi beberapa kegiatan untuk biaya promosi semen beku dan kunjungan langsung kepada peternak.

\section{Aspek produksi}

Pengembangan teknologi IB saat ini perlu dilakukan dengan memproduksi semen beku sexing yang merupakan pemisahan sperma betina $(\mathrm{X})$ dengan sperma jantan $(\mathrm{Y})$, yang merupakan peluang BIB Lembang memproduksi semen beku sexing betina dan sexing jantan sapi potong lokal, sehingga peternak tertarik membeli semen beku sexing. Untuk itu, BIB Lembang perlu berkoordinasi dengan Balai Veteriner dan Dinas Peternakan setempat dalam upaya mendapatkan pejantan bebas dari penyakit hewan menular dan Balai bisa menambah jumlah pejantan sapi lokal dengan sarana yang ada untuk memproduksi semen beku sapi potong lokal.

\section{Aspek SDM}

BIB Lembang memiliki keterbatasan dalam hal pemasaran semen beku sapi potong yang belum optimal, sehingga petugas jasa produksi yang memasarkan semen beku perlu mengikuti pelatihan atau seminar untuk meningkatkan kemampuan terkait pemasaran, sehingga penjualan semen beku sapi potong lokal dapat ditingkatkan. Selain itu untuk meningkatkan populasi sapi potong lokal perlu dilakukan peningkatan keterampilan petugas IB (inseminator), agar keberhasilan IB dapat ditingkatkan dan peternak akan merasakan hasilnya akibat bertambahnya jumlah populasi ternak.

\section{KESIMPULAN}

Dari analisis matriks IFE dan EFE dapat digambarkan dan diindikasikan posisi perusahaan stabil dalam merespons situasi eksternal, serta matriks IE menunjukkan posisi BIB Lembang dalam sel stabilitas dan pertumbuhan, dengan alternatif strategi yang dapat diterapkan yaitu penetrasi pasar dan pengembangan produk. Hasil matriks SWOT, diperoleh alternatif strategi yang akan diterapkan bagi BIB Lembang, yaitu:

a. Meningkatkan sosialisasi dan pembinaan kepada peternak dalam aspek manajemen pemeliharaan ternak, pakan, reproduksi dan manajemen kesehatan hewan.

b. Memperluas dan mempertahankan jaringan pemasaran yang sudah ada.

c. Meningkatkan kegiatan promosi semen beku sapi potong lokal.

d. Mempertahankan mutu semen beku dan meningkatkan pelayanan purna jual.

e. Memberikan pelayanan teknis kepada peternak.

f. Meningkatkan kerjasama dengan Balai Veteriner dan Dinas untuk mendapatkan pejantan lokal yang sehat.

g. Memanfaatkan teknologi untuk meningkatkan mutu semen beku sapi potong lokal.

Dari analisis matriks QSP, diperoleh strategi prioritas untuk diterapkan dalam pemasaran semen beku sapi potong BIB Lembang yaitu meningkatkan sosialisasi dan pembinaan kepada peternak dalam aspek manajemen pemeliharaan, pakan, reproduksi dan manajemen kesehatan hewan dengan total nilai daya tarik tertinggi diantara alternatif strategi lainnya.

\section{DAFTAR PUSTAKA}

Affandhy L, Yusran MA, Anggraeni YN, Pamungkas D. 2006. Kinerja Produksi dan Umur Pubertas Pedet Hasil Kawin Silang Sapi PO, Simental dan Limousin Dalam Usaha Peternakan Rakyat.Proceeding Seminar Nasional Teknologi Peternakan dan Veteriner. Puslitbang Peternakan Bogor. 
BIB Lembang. 2015. Laporan Bulanan Bulan Desember BIB Lembang 2015. Balai Inseminasi Buatan Lembang-Jawa Barat.

[BPS]. 2011. Pendataan Sapi Potong, Sapi Perah dan Kerbau 2011 (PSPK 2011). Badan Pusat Statistik. Jakarta.

[BSN]. 2008. Semen Beku Sapi. Badan Standarisasi Nasional. Jakarta.

Cooke RF, Bohnert DW, Cappelozza BI, Marques RJ, Delcurto T, Mueller CJ. 2014. Incorporation of sexed Semen Into Reproductive Management of Cow-Calf Operation. Livestock Science International Journal. May 2013, Vol 163: $165-171$

David FR. 2006. Manajemen Strategi. (Terjemahan). Prehalindo. Jakarta.

Diwyanto K, Inounu I. 2009. Dampak Crossbreeding Dalam Program Inseminasi Buatan Terhadap Kinerja Reproduksi dan Budidaya Sapi Potong. Wartazoa Volume 19 Nomor 2 Tahun 2009. Pusat Penelitian dan Pengembangan Peternakan. Bogor.

Hall JB, Glaze JB. 2013. The Used of Sexed Semen in The Beef Industry. Proceedings Applied Reproductive Strategies in Beef Cattle. October 15-16. Stanton, VA.

Indriyani NA. 2005. Strategi Pemasaran Semen Beku Sapi Potong [Tesis]. Fakultas Peternakan Universitas Gajah Mada. Ygyakarta.

Karupa E, Wolfova M, Peskovicova D, Huba J, Krupova Z. 2005. Economic Values of Traits for Slovakian Pied Cattle Under Different Marketing Strategies. Czech. Journal Animal Science. Halaman 483-492.

Mastika MI. 2003. Feeding Strategies to Improve the Production Performance and Meat Quality of
Bali Cattle (Bos sondaicus). Aciar Proceedings. No. 110. Canberra.

Putro PP. 2009. Dampak Crossbreeding Terhadap Reproduksi Induk Turunannya. Hasil Studi Klinis. Lokakarya Lustrum VIII Fakultas Peternakan UGM, 8 Agustus 2009.

Rangkuti F. 2005. Analisis SWOT Teknik Membedah Kasus Bisnis. Penerbit Gramedia Pustaka Utama, Jakarta.

Shehu BM, Rekwof P. Kezi I, Bidoli DM, Oyoduken AO. 2010. Challenge to Farmers Participation in Artificial Insemination (AI) Biotechnology in Nigeria: On Overview. Journal of Agricultural Extension, 14(2), December 2010.

Sugiyono. 2012. Memahami Penelitian Kualitatif. Penerbit Alfabeta. Bandung.

Talib C, Enwisle K, Siregar A, Budiarti, Turner, Lindsay D. 2003. Survey of Population and Production Dynamics of Bali Cattle and Existing Breeding Progress in Indonesia. Aciar Proceedings No. 110. Canberra.

Toelihere MR. 1981. Fisiologi Reproduksi pada Ternak. Penerbit Angkasa. Bandung

Utomo IC, Ciptadi G, Nasich M. 2013. Berat Lahir dan Morphometrik Pedet Umur 3-5 Hari Hasil Persilangan Antara Simental-Simpo dan Limousin-Simpo Hasil Inseminasi Buatan (IB). Fakultas Peternakan Universitas Brawijaya Malang.

Wijono DB, Hartatik, Mariyono. 2006. Korelasi Bobot Sapih Terhadap Bobot Lahir dan Bobot Hidup 365 Hari pada Sapi Peranakan Ongole. Seminar Nasional Teknologi Peternakan dan Veteriner, Puslitbang Peternakan Bogor. 